\title{
Las derivas del viajar: apuntes para un análisis itinerante de una barra del fútbol argentino
}

The drifts of travel: notes for an itinerant analysis of one Argentinian soccer supporter group

RESUMEN

Si de "barras bravas" argentinas se trata, hay una simplificación que siempre merodea la temática, me refiero al reduccionismo que las piensa como fósiles anclados en la tribuna. En oposición, este trabajo se centra en las experiencias itinerantes de los miembros de la barra del Club Atlético Belgrano de Córdoba, Argentina, autodenominada Los Piratas. El articulo explora los distintos tipos de viajes que los miembros de tal grupo realizaron durante mi trabajo de campo etnográfico. En todos estos años he podido registrar cuatro modalidades de traslados organizados: a) barriales; b) provinciales c) de infiltrados; d) de anfitriones y huéspedes. A lo largo del trabajo iré analizando cada uno de ellos para luego, al final, proponer una sistematización que resume la importancia que el viajar condensa en el proceso de formación social de Los Piratas y el involucramiento de sus miembros. Veremos que los viajes se vinculan al imperativo que tiene todo grupo social de experimentar límites.

Palabras claves: Barras, Fútbol, Viajes, Etnografía, Antropología.

\author{
Nicolás Cabrera \\ Doctor en Ciencias \\ Antropológicas (FFyH- UNC), \\ Córdoba, Argentina. \\ (UNC/IDACOR- CONICET). \\ অ nico_cab@hotmail.com \\ (1D) ORCID: 0000-0002-9360-6479 \\ $\checkmark$ Google Scholar
}




\begin{abstract}
If it is about Argentinian "barras bravas", there is a simplification that always prowls the subject, which is the reductionism that thinks of them as fossils anchored in the stand. In opposition, this paper focuses on the itinerant experiences of the Belgrano Athletic Club supporter group in Córdoba, Argentina, which self-proclaims as "Los Piratas". The article explores the different types of trips that the members of "Los Piratas" made during the author's ethnographic fieldwork. In all these years the author has been able to record four types of organized trips: a) "barriales" (blocks); b) "provinciales" (provincial); c) "de infiltrados" (of infiltrated); d) "de anfitriones y huespedes" (of hosts and guests). Throughout the work each one of them will be analyzed and then, at the end, a systematization that summarizes the importance that traveling condenses in the process of social formation of "Los Piratas" and the involvement of its members will be proposed. It will be observed how travel is linked to the imperative that every social group has to experience limits.
\end{abstract}

Keywords: Soccer supporter groups, Soccer, Travels, Ethnography, Anthropology.

\title{
Categoría, metáfora y recurso
}

omprender el proceso de formación social de una "barra
brava" argentina exige una lectura dinámica. No solo hay que
trazar múltiples temporalidades, además, se impone la tarea de acompañar la cotidianeidad itinerante de colectivos que se construyen en movimiento. Pensar a las barras ${ }^{1}$ argentinas confinadas a los estadios de fútbol es un reduccionismo espacio-temporal que alimenta una sinécdoque siempre ávida de confundir la parte por el todo, de mutilar lo diverso, de anquilosar lo procesual. Es evidente que no puede negarse la

\footnotetext{
Siguiendo a Balbi (2007) y Bermúdez (2016) propongo las siguientes aclaraciones hacia el lector o lectora para facilitar la comprensión de ciertas categorías o estrategias narrativas desplegadas a lo largo del artículo: el empleo de la cursiva se reserva para testimonios o categorías de mis interlocutores. El uso de las comillas dobles procura resaltar una palabra, extractos de medios de comunicación o bien marcar cierta ambigüedad o ironía. Además, se utilizan para citar categorías o ideas de autores. Por otra parte, todos los nombres aquí presentados son ficticios, salvo ciertas personalidades de público conocimiento como el líder máximo de Los Piratas. Una última aclaración remite a la noción barra. Cuando hable en femenino - la/s barras - me refiero al colectivo, cuando escribo en masculino — el/los barras - remito a su(s) miembro(s). Apelo a la noción de barra porque es como se autoidentifican mis interlocutores. Rechazo el epíteto de "barras bravas" por la fuerte carga estigmatizante y condenatoria que conlleva la adjetivación. Reniego de la categoría "hinchadas" como sinónimo de barra porque, al menos en mi campo, se presta a la confusión. Por "hinchada" entiendo, al igual que mis interlocutores, a la totalidad de los hinchas de un mismo equipo, sean barras o no. Con el pasar de las páginas el lector entenderá que todas estas distinciones no son simples caprichos retóricos, sino, más bien, posiciones teóricas, metodológicas y éticas.
} 
centralidad que tienen los partidos de su equipo para una barra de fútbol, pero su importancia simbólica, emotiva y moral debe ser leída desde una perspectiva relacional que contextualice tal evento en función de otros que también son constitutivos de un colectivo en permanente tránsito.

Esa mirada procesual y dinámica es la que orientó mi investigación con la barra del Club Atlético Belgrano de Córdoba -autoidentificada como "Los Piratas"- entre el 2011 y el 2018. Durante esos años acompañé y registré las vivencias de sus miembros, tanto cuando acompañaban al equipo profesional de fútbol los días de competición como en otras situaciones cotidianas que no tenían a la cancha como epicentro: reuniones semanales, salidas nocturnas, picaditos recreativos de fútbol, momentos previos o posteriores a los partidos de Belgrano, visitas a los lugares de trabajo, aniversarios, cumpleaños, velorios, juntadas en el predio del club, reuniones familiares, entre otros. Para dar cuenta de algunos de esos desplazamientos que configuran a la barra, me centré en la experiencia de viajar, pues se trata de una de las vivencias nodales que explican el carácter dinámico, tanto de la formación social de la barra, como de los procesos de adhesión de sus miembros. Los viajes son desplazamientos territoriales organizados que los miembros de la barra realizan para alentar a su equipo. Y es viajando, además de peleando, alentando o laburando (Cabrera, 2017) que Los Piratas se constituyen como tales.

Centrarse en la experiencia de viajar es fundamental en un triple sentido. Por un lado, por lo que significa desde "el punto de vista nativo". Gastón Gil, en su etnografía con la barra del Club Atlético Aldosivi de Mar del Plata, nos dice que "los viajes resumen varios de los aspectos más relevantes de las identidades de los hinchas de la hinchada" (Gil, 2007, p. 31). Vale aclarar que Gil entiende por hinchada lo que nosotros definimos como barra. Ha sido aquel antropólogo quien, a mi entender, mejor ha trabajado la centralidad que tal vivencia condensa para la cotidianeidad de una barra ${ }^{2}$. Con él entendemos que el viajar es una experiencia fundamental en el devenir barra por el que sus miembros se identifican entre diferentes y se jerarquizan entre iguales (Cabrera, 2019).

Por otro lado, James Clifford nos invita a pensar a "los viajes" como "metáfora y categoría" (Clifford, 2000). El autor norteamericano sostiene

A diferencia de otros trabajos clásicos sobre barras (Garriga Zucal, 2007; Moreira, 2001), Gil realizó una etnografía con una barra de la ciudad de Mar del Plata. Al tratarse de un equipo "alejado" de la ciudad autónoma de Buenos Aires, epicentro de la mayoría de los partidos de fútbol profesional, en su trabajo de campo debió compartir largas horas de viaje con sus interlocutores. Probablemente, esta condición de su campo se tornó una posibilidad para abordar en profundidad los viajes de la barra estudiada. En mi caso, al tratarse de un equipo de Córdoba, las distancias y horas en ruta se multiplicaron. 
que, en la disciplina antropológica, subsiste la idea de pensar al trabajo de campo como "una suerte especial de residencia localizada" (p. 34). Durante el siglo XX la antropología fue distanciándose de la idea del "viaje" para pensar en y desde campos delimitados y fijos. Como consecuencia, según Clifford, la etnografía "pasó a priorizar las relaciones de residencia por sobre las relaciones de viaje", el "estar allí" por sobre el "llegar alli" (p. 36). De lo que se trata no es de invertir la operación, sino más bien, de reconstruir las "mediaciones concretas" que nuestros interlocutores trazan en tanto "nativos" y "viajantes", pues, ambas son constitutivas de las experiencias cotidianas que aquí nos convocan.

Finalmente, apuesto a la noción de viaje como recurso metodológico. Es que ellos nos permiten, a los antropólogos, compartir largas horas con nuestros interlocutores, alimentar una mutua confianza y acceder a prácticas que de otra forma estarían vedadas a nuestra curiosidad. Cambian el modo y el contexto en el que nos relacionamos con nuestros interlocutores, por eso son otros los datos -en relación con la entrevista, por ejemplo- que construimos en nuestra interacción con ellos. Además, los viajes, permiten que se modifique la experiencia habitual del campo como un espacio físico fijo. Importan los desplazamientos y las fronteras; los escenarios y las temporalidades; las posibilidades y los límites de un "objeto" itinerante.

Recuperar la noción de viaje en tanto categoría nativa, metáfora y recurso metodológico conlleva a asumir un principio que atraviesa la propuesta del presente artículo: presentar una etnografía multilocal (Marcus, 2001) para escamotear el esencialismo representativo que prima sobre las barras producto de su aprisionamiento espacial y temporal en los estadios de fútbol durante los días de partido. Me interesa mostrar a un colectivo y a sus miembros en movimiento a partir de distintas definiciones de situaciones que se despliegan en contextos móviles, cambiantes y conectados. Sugiero pensar a los viajes como un conjunto de relaciones itinerantes y de alta densidad simbólica-emotiva en la que se producen fronteras, asimetrías, desplazamientos, prácticas, conflictos, sentimientos y experiencias que desnudan una interculturalidad ambulante.

En resumen, este artículo explora en los distintos tipos de viajes que Los Piratas realizaron durante mi trabajo de campo. En todos estos años he podido registrar cuatro modalidades de viajes: a) barriales; b) provinciales; c) De infiltrados; d) De anfitriones y huéspedes. A lo largo del trabajo iré analizando cada uno de ellos para luego, al final, proponer una sistematización que resume la importancia de la experiencia que 
el viajar condensa en el proceso de formación social de Los Piratas y el involucramiento de sus miembros.

\section{Viajes barriales}

Desde su nacimiento en 1968 hasta el día de hoy, la barra de Belgrano llega caminando a su estadio. El ritual suele replicarse cuando se juega de visitante contra un competidor de la misma ciudad. Las rivalidades cordobesas son codificadas en clave barrial. Cuando se juega el clásico cordobés de mayor relevancia, Belgrano contra Talleres, también se enfrentan sus respectivos barrios, Alberdi contra Barrio Jardín. Para entender el significado que el barrio tiene en el imaginario del fútbol argentino hay que comprender su proceso de popularización (Frydemberg, 2011). Desde la década del veinte y el treinta -en el preámbulo de la profesionalización del fútbol- ningún club puede jactarse de no tener su estadio y su barrio: su casa. El caso contrario implica una deshonra fácilmente devenida en burla. Esta característica fue diagramando una cartografía futbolera donde cada barrio tiene un color. En cada caminata que los hinchas hacen para seguir a su equipo, se adentran en la riesgosa aventura de quien se sabe invasor de un territorio que no le pertenece. Es que, el camino por el que los sectores populares masculinos se apropiaron del fútbol, ha tenido como condición necesaria la "barrialización" de las identificaciones que se defienden. En este contexto, el barrio propio se protege, se custodia, se presenta como amenazante. Y el barrio ajeno se invade, se conquista, se copa. Los territorios son botines simbólicos en permanente disputa dentro de una cartografía estructurada por una lógica bélica. Algunos de los cánticos que Los Piratas entonan en esas itineranticas urbanas dicen:

Tabla 1. Cánticos de Los Piratas

\begin{tabular}{|c|c|c|c|}
\hline A & B & $\mathrm{C}$ & $\mathrm{D}$ \\
\hline $\begin{array}{l}\text { Soy del barrio de Alberdi, me gusta el rock and roll, } \\
\text { Soy del barrio de Alberdi, } \\
\text { de la droga y el alcohol } \\
\text { Si nos dicen bolivianos, } \\
\text { tiene una explicación } \\
\text { de Bolivia traemos la droga para el descontrol } \\
\text { dicen que somos bolivianos, } \\
\text { que vendemos limones, } \\
\text { pero peor es ser gallina, } \\
\text { pecho frío y cagones } \\
\text { que yo vivo en una villa, } \\
\text { vos no estás equivocado } \\
\text { con el porro y con la pala, yo te sigo a todos lados. }\end{array}$ & $\begin{array}{l}\text { Alberdi, } \\
\text { Alberdi es } \\
\text { una joda, vino } \\
\text { puta y droga, } \\
\text { es un descon- } \\
\text { trol. }\end{array}$ & $\begin{array}{l}\text { Esta es la } \\
\text { primera barra, } \\
\text { se la aguanta } \\
\text { de verdad, } \\
\text { el que tenga } \\
\text { alguna duda, } \\
\text { que nos venga } \\
\text { a buscar. }\end{array}$ & $\begin{array}{l}\text { En Jardín } \\
\text { Espinoza, vi- } \\
\text { ven los putos } \\
\text { de Talleres, } \\
\text { para Alberdi, } \\
\text { nunca van, } \\
\text { porque les } \\
\text { tiembla la } \\
\text { pera, ayayay } \\
\text { vos corres } \\
\text { como corre } \\
\text { central. }\end{array}$ \\
\hline
\end{tabular}

Fuente: elaboración propia a partir del trabajo de campo realizado entre 2011 y 2018. 
Ser de Alberdi para los miembros de la barra es tener aguante (Alabarces, Garriga y Moreira, 2008). En las canciones "A" $\mathrm{Y}$ "B" el binomio Alberdi-aguante aparece referido a ciertos consumos: rock, alcohol y drogas (la cocaína se dice pala y la marihuana porro o chala). Alberdi es representado como un territorio donde la discontinuidad entre legalidad y legitimidad es la norma. Las transgresiones al orden normativo jurídico -traficar o consumir drogas, por ejemplo- aparecen como prácticas legítimas y cotidianas del paisaje barrial. Ellas sirven para ponderar la noción del descontrol. En la canción "C" la proclamación de aguante se torna amenaza. Este cántico es una de los más comunes a la hora de llegar a un barrio ajeno.

En la canción "D" Alberdi se presenta como terreno peligroso y temeroso para las distintas alteridades. Para la barra de Belgrano, las otredades no pueden ni quiere ingresar al barrio. La falta de valentía, honor, coraje y bravura necesaria, expresada en las nociones nativas tiembla la pera, pecho frío, gallinas y cagones no solo diferencian, también jerarquizan. Los rivales se denigran en el mismo gesto que se subalternizan. Las operaciones simbólicas para ello son la desmasculinización - putos-, y animalización -gallinas-. Una barrera de género en su sentido más amplio: un género sexualizado y un género de especie. La metáfora concluye con una extensión semántica de la simbolización que se hace sobre Talleres al resto de las alteridades (la federal y central) ${ }^{3}$.

Apelando a Goffman (2008) podemos afirmar que la barra traduce en signos de prestigio ciertos estigmas que pesan sobre el barrio. Alberdi es uno de los enclaves urbanos que concentra la mayor cantidad de inmigrantes bolivianos y peruanos de la ciudad de Córdoba. La xenofobia, el racismo y el sociocentrismo, componentes estructurales al campo del fútbol argentino, sumado a las características demográficas y socio-económicas del barrio de Alberdi, han hecho que la hinchada de Belgrano sea etiquetada despectivamente como bolivianos, bolitas, sucios o villeros ${ }^{4}$. Los Piratas retoman aquellos estigmas y los positivizan en sintonía a sus moralidades y sensibilidades. La presencia de bolivianos

\footnotetext{
"Federal" hace referencia a la policía federal y "central" al Club Atlético Rosario Central de la ciudad de Rosario.

$4 \quad$ No parece haber grandes diferencias entre la composición socio-económica de la hinchada de Talleres y la de Belgrano. Al tratarse de los clubes más masivos de Córdoba, en ambas hinchadas convergen sujetos de distintos barrios populares de la ciudad de Córdoba. Pero la diferencia es que la hinchada de Talleres se autorreferencia con el barrio Jardín Espinoza, donde está su estadio. Este último barrio contrasta radicalmente con Alberdi ya que es un barrio de clase media alta que no posee importantes contingentes de migrantes limítrofes. Con ese trasfondo sociológico debe leerse la siguiente canción que la hinchada de Talleres suele entonar: "Que feo es ser pirata boliviano / que en una villa tiene que vivir / tu hermana revolea la cartera / tu vieja chupa pija por ahí / Belgrano... / Belgrano... / Belgrano... / Belgrano no lo pienses más / andate a vivir a Bolivia / toda tu familia está allá".
} 
y peruanos seria representativa de una masiva circulación y comercialización de drogas que impera en Alberdi, lo que lleva a amplificar la representación de un barrio descontrolado en el que se vive de joda y de la cabeza. Además, el hecho de imaginar al barrio como una villa parece buscar un incremento de la peligrosidad asociada al barrio. En resumen, hay una inversión del estigma que no deja de reproducir las mayores discriminaciones que pesan sobre el barrio, la de los inmigrantes ligado al tráfico de drogas y la de los pobres con la delincuencia. Resignificar no siempre es subvertir.

Finalmente, resta decir que, para Los Piratas, las caminatas son verdaderos desfiles de poder. No solo exponen la autoridad de un colectivo que se abre paso entre el resto de los hinchas, policías, autos particulares o servicio público de transporte. Si no que, además, impone desafíos explícitos a los contrincantes mostrando una ruidosa invasión al territorio ajeno -entramos caminando y no pasó nada-, suelen cantar. También desnuda la dinámica interna de una organización siempre oscilante entre principios igualitaristas y jerárquicos. Si por un lado podríamos pensar en el carácter igualador que da la horizontalidad del asfalto, también podemos registrar asimetrías en los lugares ocupados durante la caminata. Siempre, sin lugar a excepcionalidades, la columna de Los Piratas es encabezada por su jefe histórico conocido como El Loco Tito. A sus costados están los que se conocen como la primera línea, las personas de mayor confianza del líder y mejores posicionados en la jerarquía interna. Atrás, como centro y retaguardia, suelen ir el resto de los pibes, más preocupados en poner la fiesta y el carnaval a una caminata en la que el silencio es ofensivo.

En las caminatas vemos, como dice Geertz cuando analiza las procesiones reales como dimensión carismática de la autoridad, "formas ceremoniales mediante las que los reyes tomaban posesión simbólica de sus dominios" (Geertz, 1994, p. 150). Son desplazamientos que cristalizan una estética de la autoridad que busca apropiar territorios al mismo tiempo que los resignifica. En las caminatas -y en todas las formas de viaje en general- sobrevuela la ambición soberana por extender dominios territoriales que otorgan grandeza. Copar, para ser grande, como repiten una y mil veces mis interlocutores. Seguir a Belgrano a todos lados es conquistar espacios neutrales e invadir territorios ajenos, es actualizar la cartografía bélica que ordena la geografía pirata. Y se hace ejerciendo un poder que "no solo embriaga, también exalta" (Geertz, 1994, p. 168). En los viajes se ponen en juego los mapas cognitivos y las atmosferas sensitivas con las que los hinchas de Belgrano interpretan el mundo por el que se mueven. 


\section{Viajes provinciales}

En 1968 Belgrano gana el torneo regional y se clasifica, por primera vez, a los torneos nacionales. Ese mismo año nacen Los Piratas. Una de las razones era la necesidad de organizarse para seguir a Belgrano por lo largo y lo ancho del país. Hasta el día de hoy la barra de Belgrano viaja a otras provincias en trayectos que pueden durar entre cincos o treinta horas. En estos viajes se ponen en juego disputas regionales. Las rivalidades deportivas son leídas como enemistades provinciales. Se repite la lógica polar y bélica - machista, xenófoba, animalizante, aguantadora- de los viajes barriales, solo que ahora las fronteras se desplazan junto con los barras. Cuando acompañé a Los Piratas hasta la provincia de Santa Fe en el partido disputado contra Colon, cuando caminábamos desde los micro hasta el estadio, se cantaba Hola Colon que tal como te va, es el pirata que te viene a visitar, aguante no tenés, ya lo sabés, vos sos la hinchada más puta de Santa Fe.

Los viajes provinciales también trazan otras fronteras: son mediciones que ponen a prueba el verdadero sentimiento por Belgrano. Yo no soy como esos que se quedan en casa/ Escuchando la radio para ver que lo que pasa/Yo soy hincha de Belgrano y no me cabe ninguna/Si me andan buscando miren la tribuna/ Miren a la tribuna, se canta en los colectivos que trasladan a Los Piratas por todo el país. El mismo cántico delimita entre los que se quedan en casa y los que se van a la tribuna. La diferencia deviene jerarquía cuando se sobrentiende que los segundos son los "verdaderos" hinchas de Belgrano. En esa especie de ranking de hinchas de Belgrano viajeros, la barra lidera con comodidad. Nadie recuerda algún partido oficial, sin la prohibición del público visitante, en que la barra no estuviese representada por algunos de sus miembros. Sería inadmisible para Los Piratas que en un partido de Belgrano ellos no estuviesen presentes, no ocurre lo mismo con otras organizaciones de hinchas de Belgrano ${ }^{5}$.

Hay un último nivel a considerar, pues no quiero reducir la densidad analítica de los viajes a los procesos identitarios o las clasificaciones sociales. Los viajes también son relevantes en tanto experiencias sensitivas. Los limites cruzados no solo son geográficos, ni siquiera exclusivamente

\footnotetext{
Aunque no tengan tanta visibilidad, es importante resaltar que Los Piratas no son el único grupo de hinchas de Belgrano organizados, aunque solo ellos se autoidentifican como barra. Las Filiales, la subcomisión del socio y otras agrupaciones como La 17, La banda de los trapos, La Orgaz, La banda del medio, Amas Belgrano, entre otros, son algunos de los colectivos de hinchas organizados que frecuentan por el club. La dirigencia de Belgrano organiza reuniones periódicas con estos grupos — no así con la barra- en un espacio llamado la multisectorial de las agrupaciones.
} 
identitarios. Los desplazamientos espacio-temporales de los hinchas también son corrimientos cognitivos y emocionales. Cada escenario parece llevar inscripto un "código-território" (Perlongher, 1987, p. 121) que prescribe comportamientos y sentimientos. Así como Perlongher vio que "la diferencia territorial implica también diversos "tipos" de prostitutos" (Perlongher, 1987, p. 120) nosotros podemos afirmar que el tránsito por diferentes espacios, momentos y fronteras también implica una pluralización de los "tipos" de barras. Los miembros de Los Piratas van moviéndose junto a sus "nomenclaturas classificatorias" (Perlongher, 1987, p. 152) que siempre son relacionales, contextuales y dinámicas. Son desplazamientos donde también se ponen en juego "mobilizações moleculares, no nível das sensações dos corpos" (Perlongher, 1987, p. 153).

Cada momento del viaje propone diferentes estados emocionales: desde las primeras y sosegadas horas matinales hasta el eufórico y convulsionado ingreso al Estadio. El cómo comportarse y el qué sentir siempre resulta de un complejo balance entre procesos sedimentados de larga duración y ajustes o definiciones de situaciones contextuales e inmediatas. A Los Piratas también los enlazan sentimientos mutuos. Sin embargo, la demostración de esos afectos siempre parece estar subordinada al contexto de interacción. Transcribiré un registro de mi cuaderno de campo sobre un viaje realizado a la provincia de San Juan para intentar graficar un tipo de "atmosfera sensitiva" que se puede respirar llegando al estadio visitante:

La policía nos escolta camino al estadio. A los colectivos de la barra se le suman otros cuatro que también trasladan hinchas de Belgrano. Hay siete bondis oriundos de Córdoba que desfilan por las calles céntricas de San Juan. Las motos policiales bloquean las intersecciones que nos cruzan. Las sirenas dramatizan la escena. Una vía despejada y cientos de miradas que se posan sobre nosotros. Por dentro, el colectivo es una tribuna en movimiento. Por las ventanas entreabiertas flamean banderas y camisetas celestes. En el pasillo hay saltos y arengas. Sin miedo a quebrarlas, las ventanas y los plásticos del colectivo se golpean al unísono dándole ritmo a un tema que todos, ahora sí todos, cantamos: del barrio de Alberdi yo soy, por eso a todo lado voy, te sigo a toda la Argentina, te aliento con el corazón, nunca voy abandonarte, Belgrano vos sos mi pasión, la banda quiere dar la vuelta, quiere ser campeón, oh oh oh. Miguel -miembro de la barra que viaja a mi lado- filma y le habla a una audiencia imaginada: venimos como reyes, copamos San Juan un viernes, eso es ser grande, gallina puta no me jodas, jamás vas a ser igual. 
Después de diez horas de viaje llegamos al estadio de San Martín de San Juan. Queda una hora de partido - contando el entretiempo- pero a nadie parece importarle esa ecuación. Pese a la urgencia, Los Piratas se organizan con una velocidad sorprendente. En fila descargan todo lo que había en el coche uno. Cada referente reúne a su grupo y lleva la voz de mando. El grupo de Muller custodia, en dos bolsos gigantes, los trapos de la barra. El grupo de los Bombos agarra los instrumentos. Los de Liceo distribuyen paraguas celestes y negro y banderas de mano, a mí me dan una. Los referentes gritan, esperen, no entren, vamos todos juntos. Una vez que Tito ve que todos están con lo que le corresponde encara para la tribuna. Él va al frente, a los costados algunos referentes, atrás el resto. Alrededor hay hinchas que observan atentos el desfile, sacan fotos, filman videos, alientan. Cuando nos topamos con el primer control, Tito ordena sin hablar con ningún uniformado: telones acá, instrumentos allá, todos con la entrada en la mano. Un policía le dice algo a Tito pero él lo ignora completamente. Entre los pibes hay ansiedad para entrar y empiezan algunos empujones, no pechen loco que vamos entrar todos, tranquilos dice Tito con un ojo en la barra y otro en la policía. Los últimos de la fila siguen presionando a los primeros, son sordos o pelotudos, no pechen les dije y ahora Tito está más serio y erguido. La ansiedad finalmente le gana al respeto y una avalancha enviste nuevamente contra el cordón policial. Tito reacciona, con ojos inyectados, empuja bruscamente a los de la primera fila mientras les grita en la cara no entienden la puta madre. Los ánimos se calman, la fila se ordena y la barra pasa el Cordón policial. Ver a Tito en acción enseña una máxima que ordena Los Piratas: con la fuerza del argumento o con el argumento de la fuerza.

Pasado el control policial estamos por entrar a la tribuna. Ya están colgados los trapos, casi una decena de tirantes celestes y una bandera que, colgada en el alambrado, dice Los Piratas Celestes de Alberdi. Los paraguas se abren, aunque no haya lluvia y las banderas flamean a fuerza de hombre. Dos o tres de la barra están en la tribuna abriendo el pulmón. A veces pidiendo, otras exigiendo, lo cierto es que en cada partido se deja un espacio en el medio de la tribuna para que la entrada de la barra sea más notoria además de cómoda. La barra siempre ocupa el centro de la tribuna porque es el centro del poder. Una vez más, los desfiles de poder y la estética de la autoridad. El resto de la barra, los que no estamos abriendo camino, esperamos en la antesala de la tribuna, saltando y cantando con los latidos de los bombos y los redobles de los repiques. Vayas donde vayas voy a ir, vos sos la razón de mi existir, Belgrano sos mi única pasión, te llevamos en el corazón. Adónde vas yo siempre voy, de la cabeza siempre estoy, donde jugués siempre va a estar 
la banda que te va alentar. De un momento a otro, sin previo aviso, Tito da la señal y avanzamos. A los 40 minutos del primero tiempo Los Piratas desfilan hasta la tribuna como reyes. Son el espectáculo del momento. Saltan y cantan, festejan, porque sienten cumplido el deber de estar.

Por último, además de movilizar sensaciones y estéticas, cabe resaltar que los viajes dinamizan una economía política que estructura la barra. Cada viaje tiene un costo: están los que pagan y los que cobran. Y no todos dan y reciben los mismos valores. En Los Piratas existe un acople entre desigualdades materiales y distinciones simbólicas. El primer diferencial está entre los miembros de la barra y los que no lo son. Los primeros siempre tienen mejores precios para viajar que los segundos. Pero al interior del colectivo, encontramos otras distinciones cuantificables en pesos. Mientras la punta de la pirámide usufructúa de un excedente socialmente producido, la base gasta más de lo que recupera. Esta suma de saldo negativo no quiere decir que los pibes no encuentran en la economía de la barra un seductor sistema de compensaciones. La economía informal de la barra siempre ofrece mejores precios que cualquier otro transporte de la economía legal -además de incluir la entrada a los partidos-. Además, en muchos testimonios de barras pertenecientes a los sectores populares de la sociedad cordobesa, el ritual de viajar siguiendo a Belgrano viene acompañado de la experiencia de conocer el país o, incluso, salir de él-como sucedió cuando Belgrano jugó en Brasil o en Chile-. Una posibilidad vedada para muchos de ellos sino fuese por sus vinculaciones con la barra. Lo que quiero decir es que esa economía informal de la barra, al mismo tiempo que reproduce desigualdades, posibilita compensaciones.

\section{Viajes de infiltrados}

La prohibición al público visitante por "razones de seguridad" ante la escalada de violencia -en el ascenso desde el 2007 y en la primera división desde el 2013- modificó sustancialmente las dinámicas de las barras argentinas ya que quedó relativamente suprimida la posibilidad de viajar a otros estadios. Digo "relativamente" porque las barras nunca dejaron de seguir a su equipo de visitante. Por un lado, porque la prohibición no es absoluta. Hay muchos partidos que todavía se disputan con las dos hinchadas: amistosos, clásicos de verano, Copa Argentina y torneos internacionales. Pero fundamentalmente porque, aun vedadas, las barras siguen viajando. Lo que produce la prohibición del público visitante es la reconfiguración de la experiencia de viajar: una ley prohibitiva no extingue una práctica sedimentada por décadas, obliga a ajustes. 
Los Piratas transgreden la prohibición al público visitante en nombre de la pasión. La ley del hincha está por encima de la norma jurídica. Cuando se trata de pocas barras que se lanzan a seguir a Belgrano, viajan como "infiltrados". Es decir, están mezclados entre los hinchas del equipo local, intentando disimular su condición de hinchas de Belgrano. En este caso, suelen ser miembros de la barra que viajan con dos, tres o cinco personas más. A veces son promesas planeadas con tiempo, en otras oportunidades son simples arrebatos espontáneos. Lo más común es que vayan en autos propios y con entradas gestionadas en el club. De eso nos cuenta Momo, un miembro de Los Piratas grupalmente reconocido por viajar a todas las canchas, inclusive en la era de la prohibición al visitante.

Infiltrado no sé... no sé si llamarlo así, yo me siento, yo voy a seguir a mi equipo. Soy un apasionado del fútbol, un apasionado del tablón, no solo de mi equipo, me gusta ver gente que lo vive como yo, me gusta aprender cosas. Me gusta ver como se mueven los demás para tomar lo bueno y dejar lo malo, ver los errores, que te sirven para tu tribuna. Mejorar cosas y no cometer errores en otra. También porque de local muchas veces no lo veo al partido, porque estoy con otras cosas de la barra, que el bombo, que el telón y de visitante lo puedo ver, apreciar mejor, por eso voy sin importar el resultado, juegue donde juegue (...) generalmente vamos con los que sabemos que van siempre, amigos, mis hermanos, pero siempre pensamos antes cómo vamos a entrar. Siempre, antes de salir, nos preguntamos ¿cómo vamos entrar? Nos aseguramos la entrada a la cancha con tiempo. Llamamos algún amigo ligado al club, nos hacemos pasar por periodistas, hablamos con Tito, siempre buscamos una alternativa, algún contacto, nos la rebuscamos como quien dice. (Momo, entrevista, 10 de mayo del 2017)

A Momo no le cierra que le digan "infiltrado", una categoría más condenatoria que descriptiva y que hoy pulula en los medios de comunicación argentinos. Pues en los últimos años se ha convertido en una etiqueta imputable a cualquier hincha que está "invadiendo" un territorio que la ley prohíbe. Un indeseado, clandestino, encubierto, que como tal representa una amenaza en sí misma. Como todo invasor, es merecedor de un castigo. Los casos de golpiza y linchamiento para los "infiltrados" vienen aumentando en el fútbol argentino. Curiosamente, dicha figura es una "desviación" creada por una norma (Becker, 2009) o, para remarcar aún más la contradicción: es una etiqueta que produce violencia como consecuencia de una ley que busca evitarla. Y para Momo, como para cualquier hincha de Belgrano, la noción de 
"infiltrado" ya tiene una carga triste y dolorosa que inevitablemente remite al asesinato de Emanuel Balbo ${ }^{6}$.

Momo sostiene que sigue a su equipo por muchas razones y de diferentes formas. Le gusta verlo jugar, algo que la mayoría de los miembros de Los Piratas no hacen cuando Belgrano juega de local. Hay un goce en el acto de presenciar fútbol, aunque se diga que el resultado es anecdótico. Pero además se viaja para aprender cosas sobre las tribunas. Es que la mayoría de los barras son críticos agudos del desempeño que cada hinchada tiene en su tribuna. Siempre están comentando sobre canciones, banderas, ritmos, salidas o bombos. Las tribunas son espejos donde las barras se comparan. Obviamente, suelen ser muy ligeros para los elogios propios y los defectos ajenos, pero eso no impide que, en determinados casos, haya profundas autocríticas o felicitaciones a terceros. Ambos registros, entonces, el partido y la tribuna, parecen mezclarse en el testimonio de Momo. Cuando lo escucho hablar me remite a un jugador de fútbol que hace de la tribuna un partido, donde hay que mejorar cosas y no cometer errores. Resuena una idea que es un lugar común a la hora de hablar de las barras argentinas, pero no por eso deja de ser menos verdadero: Los Piratas replican en las tribunas la competencia que se disputa en el campo de juego. Hay una performance de banderas, cantos, silencios, silbidos, ritmos o coreografías a partir del cual los hinchas participan activamente del espectáculo deportivo.

Momo también menciona el desafío que implica entrar al estadio visitante. Para tal tarea se despliega una agenda de contactos y un repertorio de rebusques. Asegurarse la entrada implica activar una red de reciprocidades ligadas a los desplazamientos que tiene en la vida cotidiana del club. Me refiero a intercambios que exceden por lejos a la barra pero que no la excluyen. Porque Momo y los que siempre viajan, a la hora de entrar, piden a dirigentes, socios, Tito o periodistas allegados a Belgrano, un reconocimiento por el laburo invertido en el club. En calidad de "verdaderos hinchas" exigen privilegios que perciben como derechos. Lo que quiero decir es que viajar de "infiltrado" no solo es deseable para los apasionados, también es posible para los conectados y merecidos.

\footnotetext{
Emanuel Balbo fue un hincha asesinado el 15 de abril del 2017. Belgrano jugaba de local contra el clásico Talleres en un partido oficial, en el Estadio Mario Alberto Kempes, con la prohibición del público visitante vigente. En la popular Willington, al frente de la tribuna pirata y donde normalmente están los hinchas de Talleres, se produjo una discusión entre hinchas de Belgrano. Oscar "Sapito" Gómez comenzó a gritar que Emanuel Balbo era un hincha de Talleres "infiltrado". Varios hinchas de Belgrano comenzaron a golpearlo hasta arrojarlo por una de las bocas de ingreso a la tribuna. A los dos días murió en el Hospital de Urgencia de la ciudad de Córdoba. Balbo no fue el primer caso de golpiza a un hincha etiquetado como "infiltrado" pero sin duda fue el más espectacularizado por los medios de comunicación.
} 
Y casi siempre lo consiguen. Esto demuestra que los "favores" intercambiados entre, por ejemplo, dirigentes y barras, encuentra en la figura del "infiltrado" una vía más de materialización.

\section{Viajes de anfitriones y huéspedes}

La otra modalidad común en la era de la prohibición del público visitante, son los viajes que se hacen tras un acuerdo previo entre las barras de los dos equipos que van a jugar. Estos viajes suelen ser en traffic donde se embarca la primera línea, es decir, la cúpula de Los Piratas. La invitación no es para cualquiera. Generalmente, la barra que esta de local recibe a la visitante con asado, bebida y entradas. Una generosidad que obliga, pues se espera una futura inversión de roles cuando los mismos equipos jueguen en Córdoba. A diferencia de viajar infiltrados, en los encuentros de barras no se esconde la identidad provincial o la pasión por el club, pero sí se la regula. Es que, en estos casos, las dos barras presencian el partido juntas en la tribuna local, lo que exige un comportamiento particular del visitante. Se trata de respetar a quien te abre las puertas de su casa. $\mathrm{Al}$ igual que en la modalidad anterior, son experiencias dignas de fotografiar para compartir en las redes sociales, pues ¿de qué sirve arrogarse ser los verdaderos hinchas de Belgrano sino se presentan pruebas?

Esta forma de viajar incluye un sistema de derechos y obligaciones que Momo describe como códigos de barras. Se trata de un pacto de no agresión por el que las viejas rivalidades, o se esfuman, o se ponen entre paréntesis en pos de seguir al equipo que cada uno representa. Es un intercambio reciproco de dones mediado por un respeto territorial entre anfitriones y huéspedes. Está lejos de ser un fenómeno totalmente nuevo, pues la amistad entre barras diferentes tiene una larga lista de ejemplos. Verónica Moreira ya lo expuso de manera rigurosa y creativa con la barra de independiente (Moreira, 2001). Pero esta vieja tradición de recibir barras amigas antiguamente se reducía a unos pocos casos que respondían al síndrome de Beduino ${ }^{7}$ (Moreira, 2001). Hoy, el mapa de las rivalidades se ha trastocado sustancialmente. El síndrome de Beduino no desaparece, se suspende momentáneamente.

Para que tal proceso sea posible operan, al menos, dos factores: el primero ya lo dije: la prohibición del público visitante. La ley ha tenido efectos colaterales paradójicos en relación con la violencia: si por un lado la aumenta incrementando los conflictos entre hinchas del mismo equipo

El amigo de un amigo es un amigo, el enemigo de un enemigo es un amigo; el amigo de un enemigo es un enemigo; el enemigo de un amigo es un enemigo. 
o creando la figura del "infiltrado"; por otro lado, refuerza viejas amistades entre barras al tiempo que posibilita otras. Lo cierto es que hoy, entre asados, vinos y camuflaje neutral, se dan "ritos de comensalidad" (Moreira, 2001, p. 91) entre viejos enemigos que se estrechan manos para continuar viajando. Con la prohibición vigente, se torna imprescindible un cordial recibimiento - con previo aviso y organización- de la barra local hacia la visitante para poder "burlar" la proscripción. Y solo sabiéndose comportar en la casa ajena la troca sobrevive al tiempo. Una gentileza que obliga para perdurar. En un intercambio entre dueños de casa e invitados, sobre territorios propios y extraños, las barras argentinas dan y reciben, entre ellas, lo que esperan del resto: respeto. Como bien lo expresa Pitt-Rivers en su trabajo sobre las comunidades mediterráneas:

Un anfitrión lo es sólo en el territorio sobre el que en una ocasión determinada tenga derechos a la autoridad. Fuera de él no puede mantener su papel (...) [el huésped] contrae el derecho y la obligación de devolver la hospitalidad en el futuro en territorio en que tenga derecho a la autoridad. Así la reciprocidad entre anfitrión y huésped se transpone en una secuencia temporal y una alternancia espacial en que los papeles se invierten. (Pitt-Rivers, 1979, p. 99)

Los códigos que menciona Momo son los del anfitrión y el huésped, una relación que, al mismo tiempo que refuerza las identidades territoriales, permite cruzarlas.

El segundo factor que dinamizó un acuerdo generalizado de no agresión entre las barras y que hasta hoy permite que ellas sigan viajando de visitante, fue la experiencia de Hinchadas Unidas Argentinas (HUA) ${ }^{8}$. Aquella aventura hoy extinta, significó un acuerdo explícito entre más de cuarenta barras de diferentes categorías y provincias para, según dijo su creador Marcelo Mallo, erradicar la violencia en el fútbol, acompañar a la selección argentina y trabajar políticamente para el gobierno kircherista que estaba en el poder. Lo más importante sobre la experiencia de HUA a los fines del presente artículo, fueron las vivencias en torno al Mundial de Sudáfrica 2010. La idea de acompañar a la selección argentina como la hinchada oficial, implicaba, para los barras, hacer lo mismo que hacen con su equipo: organizarse colectivamente y gestionar los recursos necesarios para viajar adonde la selección juegue. Una vez conseguido 
lo imprescindible, cada barra escogía a sus representantes que iban a viajar a Sudafrica. Ya en continente africano, convivieron, por semanas, cantando a favor de Argentina, las Malvinas, Maradona o la selección y en contra de los chilenos y los ingleses. En varios videos se puede ver a HUA cantando, en Sudáfrica, Esta es la banda loca de la Argentina la que de las Malvinas nunca se olvida La que deja la vida por los colores la que les pide huevos a los jugadores Para ser campeones. Finalmente, hubo una última experiencia que afianzó solidaridades entre barras diferentes. Varios de ellos, entre los que se cuentan los de Belgrano, estuvieron detenidos en Sudáfrica para después ser deportados. Según varios miembros de la barra, la vivencia de estar preso en un país extraño, de lengua incomprensible para muchos de ellos, alejados de la familia y con un futuro inmediato incierto, reforzó solidaridades y amistades.

La existencia de HUA incluyó un proceso por el que los referentes de las barras de cada equipo empezaron a reconocerse como pares. La identificación -con su correspondiente jerarquización- se construyó sobre reciprocidades reguladas por códigos comunes. En ese proceso el viaje a Sudáfrica fue nodal. Porque allí, no solo tomo cuerpo y nervio la hinchada de la selección. Sin desdibujarse las coordenadas barriales, provinciales y regionales que condensa cada club, en la Copa Mundial de Sudáfrica 2010 hubo un gran paragua aglutinador de semejante heterogeneidad: la patria. Una vez más, como desde su nacimiento, el fútbol se convertía en un "operador de nacionalidad" (Alabarces, 2008, p. 27) sobre el que se suspendían viejos conflictos. Se hacen amigos a fuerza de códigos en común forjados al calor de vivencias grupalmente experimentadas. Barras históricamente enemistadas o indiferentes, se hicieron amigas viajando. No es de extrañar que para viajar tengan que seguir siendo amigos.

\section{Comentarios finales}

Los viajes son desplazamientos que trazan contornos en diferentes sentidos. Igualan, diferencian, jerarquizan y distinguen en múltiples dimensiones. Estamos frente a experiencias constitutivas de Los Piratas en, al menos, cuatro niveles distintos pero complementarios:

1- Consagran diferencias entre los "verdaderos hinchas" de Belgrano y los que no lo son. En el imaginario del fútbol argentino, viajar de visitante -experiencia reflejada en expresiones por demás comunes como ir a todos lados, seguir al equipo adonde vaya, alentar en todas las canchas, entre otras- es una prueba en la que los hinchas renuevan 
el contrato pasional con el equipo. Como decía un interlocutor, se da todo sin esperar nada. Los viajes son termómetros de la incondicionalidad, lealtad y compromiso con el equipo, de ahí que viajar los torna "más hinchas". Como toda competencia necesita de mediciones, trofeos y reconocimientos. El mérito del viaje es proporcional a las proezas vividas: la adversidad se afronta, la distancia se relativiza, el reto se supera y el logro se festeja. Y todo se comunica. El anecdotario de viajes o las imágenes, propias o ajenas, se atesoran como pruebas irrefutables. Los Piratas, que viajan a todos lados desde 1968, se sienten los "verdaderos" hinchas de Belgrano.

2- Configuran a la barra trazando contornos, solidaridades, alteridades, intercambios y asimetrías. Unen, diferencian, jerarquizan y conectan. Viajando se sabe el lugar que le corresponde a cada uno. Es una vivencia que mide pertenencias, méritos y desigualdades al interior de Los Piratas. Nadie puede ser considerado parte sino viaja con ellos. Los viajes permanentemente refuerzan un sentimiento de pertenencia colectiva: canciones, anécdotas o chistes son narrativas que, como dice de Certeu, "no se limita[n] a expresar un movimiento. Lo hace[n]" (de Certeu, 2000, p. 90). Lo mismo puede decirse de los tatuajes, la ropa, los consumos, los colectivos, los bombos o las banderas. Son marcas diacríticas de una pertenencia que se torna tan material como visible. Pero los viajes no solo dibujan fronteras de identificación y diferencia, también demarcar desigualdades: quién puede reservar pasajes y por cuánto, quién cobra y quién paga, dónde se viaja y con quien, qué función tiene cada uno, al lado de quién se camina, cuantas veces viajó, quién cuenta historias, quién las escucha, de que se ríen, cuando hay silencios, quién puede hablar con la policía y de qué manera, quién es requisado y quien no; son simplemente algunas de las preguntas que se disparan a partir de la experiencia itinerante de viajar, y que expresan las asimetrías constitutivas de un colectivo vertical y jerárquico. Son momentos de socialización que enlazan personas al mismo tiempo que distinguen y ponderan. Me interesa enfatizar que los viajes son instancias privilegiadas para captar un organigrama de la barra que se construye en movimiento. Pero Los Piratas distan mucho de ser un colectivo encapsulado y ensimismado. Los viajes también desnudan la amplia red de intercambios y reciprocidades que una barra va tejiendo mientras se mueve. Viajando Los Piratas se conectan. Policías, dirigentes, agrupaciones de socios, barras de otros equipos, periodistas, jugadores $\mathrm{u}$ organizaciones políticas son algunos de los contactos que mis interlocutores agencian para seguir a Belgrano. 
3- Son procesos de subjetivación. Construyen género: viajando Los Piratas se hacen varones heterosexuales y adultos. Pero, además, en ese proceso de generización, también producen y reproducen otros marcadores sociales vinculados a categorías clasificatorias, identificaciones y vivencias locales, regionales y globales. Son desplazamientos atravesados por una "geometría del poder" (Massey, 2000, p. 179) que siempre puede ser pensada desde diferentes marcadores sociales. La identificación más clara es la de género: el viajar es una experiencia del devenir hombre. Es un momento donde se prueba la hombría de cada miembro. Pero no en relación con cualquier prototipo, sino en referencia a aquel que prescribe a la masculinidad heteronormativa y adulta como ideal y deber. Como ya lo dijo Archetti (1984), las tres grandes alteridades a subordinar en el fútbol son las mujeres, los niños y los homosexuales. Pero también hay una geopolítica en disputa. A medida que cruzan fronteras geográficas, las reafirman. Es que Viajando se consagran como sujetos de barrios populares, cordobeses y argentinos. Cuando caminan a barrio jardín, lo hacen en el nombre de barrio Alberdi; si viajan a jugar contra los porteños o rosarinos se presentan como cordobeses; y a la hora de insultar a brasileros, chilenos o ingleses enfatizan su argentinidad. Identificaciones glocales. Parafraseando a Pablo Alabarces, por más globalizado, massmediatizado y espectacularizado que el fútbol esté, las narrativas de los hinchas siguen necesitando de diferentes territorios donde anclarse.

4- Condensan dinámicas emocionales e intercambios económicos que no pueden ser reducidos a una perspectiva de la "identidad". Me interesa recuperar dos dimensiones que suelen ser excluidas cuando el punto de partida es, igual que el de llegada, una acción social y un proceso de adhesión orientado únicamente por una racionalidad valorativa o "simbólica". Los viajes también son relevantes en tanto experiencias sensitivas. Son actividades miméticas donde las emociones no se liberan, se construyen. Toda esta carga emotiva no tiene que llevarnos a pensar que se trata de una práctica desprovista de regulación. Vale recordar la noción elisiana de "descontrol controlado" (Elias y Dunning, 1995). Viajar es, como dice Momo, saber ubicarse. Comprender que hay emociones válidas para cada contexto y situación.

Los viajes también tienen una dimensión económica que permiten compensar ciertas asimetrías estructurales que muchos miembros de la barra tienen por su ubicación desfavorable en un espacio social desigualmente estratificado. Por un lado, ponen en marcha toda una economía subterránea (Bourgois, 2010) que deja un excedente monetario acumulado y distribuido en el vértice de la barra. Por otro lado, 
algunos de la primera línea pueden conseguir descuentos o formas de pago más accesibles y flexibles que cualquier otro régimen monetario de la economía legal. Finalmente, aquellos más desconocidos entre los barras, aun pagando el precio más caro, siguen ahorrando una importante cantidad de dinero en relación con el precio que se pagaría para viajar en un colectivo de línea o en otro ómnibus de "hinchas comunes", además, solo la barra ofrece la entrada al partido. Estos facilitadores han permitido que muchos de nuestros interlocutores me comentaran que gracias a Belgrano y la barra han recorrido el pais o salido de él. Haber viajado por casi todas las provincias de la Argentina o al exterior, siguiendo a Belgrano, es una experiencia que no se veía en el horizonte de lo posible de muchos de mis entrevistados si no fuese por la barra. Claramente en los viajes se cristaliza toda una "economía subterránea (no sujeta a impuestos)" (Bourgois, 2010, p. 31) que a algunos les significa "métodos alternativos de generación de ingresos" (p. 33) y a otros unos sistemas compensatorios de acceso a bienes, servicios y experiencias que la economía formal les veda debido a su subalternidad estructural. Pero para la enorme mayoría de Los Piratas los gastos siempre superan a los ingresos. Lo que la barra posibilita es que esos gastos se amortigüen mediante un sistema de solidaridad organizada e intercambios de favores. Y los que lucran por aquel sistema son una ínfima minoría que detenta los espacios de más alto nivel jerárquico. Porque la barra, como la mayoría de los grupos humanos, no deja de estar atravesado por relaciones socio-económicas y simbólicas que oscilan entre el trabajo cooperativo y la apropiación desigual del excedente producido.

A lo largo del texto he querido demostrar que viajar es, entre Los Piratas, una "experiencia común, aunque no necesariamente es una experiencia compartida entre ellos" (Segura, 2015, p. 70). Hay modos de ver, hacer y sentir que "persisten" en el espacio y en el tiempo. En paralelo, también hay "variabilidad" en las vivencias que cada barra despliega en los distintos escenarios por los que se mueve. La barra viaja entre lo articulado históricamente y lo vivido subjetivamente. Viajar muestra que hay cambios dentro de la continuidad. Raymond Williams, también citado por Ramiro Segura, sostiene que "la persistencia indica alguna necesidad permanente" (Segura, 2015, p. 71) Me animo a decir que la necesidad persistente que condensan los viajes se vincula al imperativo que tiene todo grupo social de experimentar límites. Los limites, o fronteras, son relaciones sociales objetivadas en el espacio. Remiten a sentimientos y clasificaciones, flujos y confines, identificaciones y alteridades, afinidades y enemistades, enclaves e itinerancias que posibilitan la formación de un grupo. Principios de visión y división diría Bourdieu. 
Frederik Barth (1976), en su análisis de las relaciones interétnicas, sostuvo que los límites a partir de los cuales se formaban dos grupos distintos no se debían a la ausencia de interacción entre los mismos. Todo lo contrario. Es en la "estructura de interacción" (Barth, 1976) entre grupos diferentes donde esos límites se experimentan y, por ende, donde los grupos se reconocen como tales al mismo tiempo que se distinguen de sus alteridades. Atravesando espacios, Los Piratas experimentan límites que unen, separan y jerarquizan. Procesos sociales que, entre lo articulado y lo vivido, les permiten existir.

\section{Referencias bibliográficas}

Alabarces, P. (2008). Fútbol y patria. Buenos Aires: Prometeo libros.

Alabarces, P., Garriga, J. y Moreira, V. (2008). El aguante y las hinchadas argentinas: una relación violenta. Horizontes Antropológicos, 14(30), 113-136. Recuperado de http://www.scielo.br/pdf/ha/v14n30/a05v1430.pdf

Archetti, E. (1984). Fútbol y ethos. Buenos Aires: Flacso.

Balbi, F. (2007). De leales, desleales y traidores: valor moral y concepción de politica en el peronismo. Buenos Aires: Antropofagia.

Barth, F. (1976). Introducción a Los grupos étnicos y sus fronteras. La organización social de las diferencias culturales. México: Fondo de Cultura Económica.

Becker, H. (2009). Outsiders. Hacia una sociología de la desviación. Buenos Aires: Siglo Veintiuno Editores.

Bermúdez, N. (2016). "De morir como perros" a "me pinto solo cuatro uñas". Una mirada antropológica sobre crueldad, moralidad y política en muertes vinculadas a la violencia institucional en Córdoba (Argentina). Revista Publicar en Antropología y Ciencias sociales, 14(30), 9-27.

Bourgois, P. (2010). En busca de respeto: vendiendo crack en el Harlem. Buenos Aires: Siglo XXI Editores.

Cabrera, N. (2017). Las resonancias del pasado: apuntes para un estudio diacrónico y sincrónico de una hinchada del fútbol argentino. Revista FuLiA, 1(2), 6- 27.

Cabrera, N. (2019). Que la cuenten como quieran: una etnografía sobre el devenir barra. Córdoba (Tesis de doctorado). Universidad Nacional de Córdoba, Córdoba, Argentina.

Clifford, J. (2000). Culturas viajantes. En A. Arantes (org.), O espaço da diferença (pp. 51-79). Campinas: Papirus.

De Certeau, M. (2000). La invención de lo cotidiano. 1 Artes de hacer. México D. F: Universidad Iberoamericana.

Elias, N. y Dunning, E. (1995). Deporte y ocio en el proceso de la civilización. Madrid: FCE.

Frydenberg, J. (2011). Historia social del fútbol del amateurismo a la profesionalización. Buenos Aires: Siglo XXI Editores.

Gil, G. (2007). Hinchas en tránsito: violencia, memoria e identidad en una hinchada de un club del interior. Mar del Palta: EUDEM. 
Geertz, C. (1994). Conocimiento local. Ensayo sobre la interpretación de las culturas. México: Paidós.

Goffman, E. (2008). Estigma: La identidad deteriorada. Buenos Aires: Amorrortu.

Marcus, G.E. (2001). Etnografía en/del sistema mundo. El surgimiento de la etnografía multilocal. Alteridades, 11(22), 111-127.

Massey, D. (2000). Um sentido global do lugar. En A. Arantes (org.), O espaço da diferença (pp. 176-185). Campinas: Papirus.

Moreira, M.V. (2001). Honor y gloria en el fútbol argentino: el caso de la Hinchada del Club Atlético Independiente (tesis de grado). Universidad de Buenos Aires, Buenos Aires, Argentina.

Perlongher, N. (1987). O Negócio do Michê: prostituição viril em São Paulo. São Paulo: Brasiliense.

Pitt-Rivers, J. (1979). Antropología del honor o política de los sexos. Barcelona: Crítica.

Segura, R. (2015). Vivir Afuera: antropología de la experiencia urbana. Universidad Nacional de San Martin: UNSAM EDITA. 